\title{
Effect of Moringa Leaves Powder Consumption on Young Children Nutritional and Serum Retinol Status in Burkina Faso Rural Area
}

\author{
Urbain Zongo, ${ }^{1,}$, Boubacar Savadogo ${ }^{2}$, Steve Leonce Zoungrana ${ }^{3}$, Dia Sanou ${ }^{4}$, Aly Savadogo ${ }^{1}$, \\ Mamoudou Hama Dicko ${ }^{1}$, Alfred SababenedyoTraore ${ }^{1}$ \\ ${ }^{1}$ Center for Research in Biological, Food and Nutritional Sciences, University Ouaga 1 Pr Joseph KI-ZERBO, Ouagadougou, Burkina Faso \\ ${ }^{2}$ Institute for Health Sciences Research, National Center for Sciences and Technology Research, Ouagadougou, Burkina Faso \\ ${ }^{3}$ Departement of Gastroenterology, Regional University Hospital Center, Ouagadougou, Burkina Faso \\ ${ }^{4}$ Food and Agriculture Organization of the United Nations (FAO), Addis Ababa, Ethiopia
}

\section{Email address:}

Urbain.zongo@gmail.com (U. Zongo),sbouba7@yahoo.fr (B. Savadogo),zoungleonce@yahoo.fr (S. L. Zoungrana), desanou@yahoo.fr (D.Sanou), alysavadogo@gmail.com (A. Savadogo), mamoudou_dicko2004@yahoo.fr ( M. H. Dicko), astraore@gmail.com (A. S. Traoré)

${ }^{*}$ Corresponding author

\section{To cite this article:}

Urbain Zongo, Boubacar Savadogo, Steve Leonce Zoungrana, Dia Sanou, Aly Savadogo, Mamoudou Hama Dicko, Alfred SababenedyoTraore. Effect of Moringa Leaves Powder Consumption on Young Children Nutritional and Serum Retinol Status in Burkina Faso Rural Area. International Journal of Nutrition and Food Sciences. Vol. 7, No. 4, 2018, pp. 148-154. doi: 10.11648/j.ijnfs.20180704.16

Received: July 19, 2018; Accepted: August 1, 2018; Published: August 29, 2018

\begin{abstract}
The promotion of the consumption of indigenous plant species with high nutritional value is an important nutrition intervention in Africa rural areas. The current student was a randomized control trial of two groups ( ${ }^{\phi} \mathrm{Gm}$ and ${ }^{\phi} \mathrm{Gm}$ ) with a baseline and an endline evaluation after 12 weeks. A total of 119 pre-school children received Moringa leaf powder and changes in vitamin A and anthropometric indicators of children were assessed against changes for control group children. After 12 weeks, the mean WHZ reflecting acute malnutrition declined in both groups. The mean WHZ decreased from -2.31 z-score to $-1.86 \mathrm{z}$-score in group $1\left({ }^{\phi} \mathrm{Gm}\right)$ and $-2.20 \mathrm{z}$-score to $-1.88 \mathrm{z}$-score in group $2\left({ }^{\dagger} \mathrm{Gm}\right)$ receiving Moringa as a dietary supplement with a statistically significant decrease in groups $(p<0.001)$. The mean serum retinol concentration in children was below the cut-off defining VA deficiency $\left(<0.7 \mu \mathrm{mol} . \mathrm{L}^{-1}\right)$. The baseline prevalence of VA deficiency was $56.8 \%$ in group 1 and $53.8 \%$ in group 2. Mean retinol concentrations increased significantly from $0.64 \mu \mathrm{mol} . \mathrm{L}^{-1}$ to $0.73 \mu \mathrm{mol} . \mathrm{L}^{-1}(\mathrm{p}<0.001)$ in Group 1 ( ${ }^{\phi} \mathrm{Gm}$ (Control) and from $0.64 \mu \mathrm{mol} . \mathrm{L}^{-1}$ to $0.74 \pm 0.05 \mu \mathrm{mol} . \mathrm{L}^{-1}$ (p $\left.<0.001\right)$ in group $2\left({ }^{\phi} \mathrm{Gm}\right)$. Significant increase was observed regardless of gender in both groups. The change between groups was not statistically significant $(\mathrm{p}=0.838)$. Our findings showed that the intervention was not effective enough in the change in serum retinol status in children $(p=0.379)$. The change in serum retinol was significantly influenced by serum retinol concentration at baseline. Therefore, the promotion of Moringa leaf consumption should be complemented by additional approaches to increase VA intake, as well as through public health measures such as deworming programs, to enhance its effectiveness in the fight against VA deficiencies and many other micronutrients.
\end{abstract}

Keywords: Nutritional Status, Serum Retinol, Moringa Oleifera, Dietary Diversification

\section{Introduction}

Micronutrient deficiency including vitamin A remains a public health problem in Burkina Faso. Since the first International Conference on Nutrition in 1992 food based interventions for the fight against micronutrient deficiencies were recommended [1]. Therefore, the consumption of indigenous food including animal and plant species with high nutritional value in dietary habits is promotion.

Dietary diversification is particularly appropriate for the 
control of vitamin A deficiency, because of the existence of a large number of foods rich in vitamin $\mathrm{A}$ and pro-vitamin $\mathrm{A}$, and in addition to increasing vitamin A status, dietary diversification appears to result in a better overall nutritional status [2]. Wasanwisut et $a$ l. showed that daily supplementation of green leaves and orange fruits and vegetables, as well as fat increase both the serum retinol and the retinol content of lactating milk in northeastern Thailand [3]. Green plant foods rich in proteins, vitamins, minerals, polyphenols, like the leaves of Moringa oleifera Lam. (Moringaceae) can be used for the prevention and correction of acute malnutrition because of their exceptional nutritional qualities [4-6].

Previous studies have identified cooked leafy vegetable sauces as one of the main sources of micronutrients for school-age children in Burkina Faso. A preliminary study in Burkina Faso found that $85.5 \%$ of preschool children's mothers know Moringa and its associated beneficial effects, it is culturally accepted by most ethnic groups, but the processing methods are not adequate [7].

In view of the important results on the consumption of Moringa leaves powder in the nutritional recovery from severe acute malnutrition [6], in clinical studies of malnourished and HIV positive [8, 9], consumption of Moringa leaves powder should be encouraged to improve the nutritional status of children, and prevent against some micronutrient deficiencies as iron and Vitamin A in view of the nutritional value of its leaves commonly used in Burkina Faso [6].

Our study report a method of plant species (Moringa oleifera) intervention in the rural nutrition sector and to prevent malnutrition and specific micronutrient deficiency (vitamin A).

The objectives of this study was (i) to assess the effect of Moringa leaves powder consumption on the overall nutritional status of preschool children, (ii) to assess the effect of Moringa leaves powder consumption on serum retinol concentration in the same children.

\section{Methodology}

\subsection{Study Design and Subjects}

The study was conducted in the rural district of Gaongo, Province of Bazega in the south-central part of Burkina Faso. It was a randomized control study ( ${ }^{\mathrm{G}} \mathrm{Gm}$ and $\left.{ }^{\phi} \mathrm{Gm}\right)$ with an endline evaluation after 12 weeks.

A total of 119 children aged 12-59 months were randomly selected and assigned in two groups. Group $1\left({ }^{(} \mathrm{Gm}\right)$ was on a regular diet (control sample) and Group $2\left({ }^{\phi} \mathrm{Gm}\right)$ received Moringa leaves powder (treatment sample).

The research protocol was approved by the Ethical Committee for Health Research of Burkina Faso. Informed consent was obtained from parents prior to children's enrolment. At baseline all participants received $500 \mathrm{mg}$ anthelmintic drug (mebendazole) in order to reduce parasite load. The last VA and anthelmintic supplementation in the study area was six months before the intervention. The amount of Moringa leaves powder to be incorporated was determined according to the daily intake recommended by
FAO $[10,11]$ and organoleptic tests carried out in the health centers [12]. Thus, participants in the treatment group ( $\left.{ }^{\phi} \mathrm{Gm}\right)$ received $30 \mathrm{~g}$ of Moringa oleifera leaves powder daily during meals for 12 weeks. Moringa leaf powder was used to sprinkle meals before eating. The $30 \mathrm{~g}$ were distributed among the meals consumed during the day. This strategy was more conducive to consumption and avoided discards.

Weekly appointments were held to check the nutritional status of the children, motivate the mothers in relation to their children's diets, but also to make them aware of their general health status.

\subsection{Data Collection}

\subsubsection{Socio-Economic Characteristic}

Socio-economic characteristics including marital status, mother's level of education, religion, ethnicity, main professional activities, sources of income, sources of drinking water, and sanitation at the household level were collected through a semi-structured interview. In addition, data on the level of knowledge and use of vitamin A rich foods rich such as Moringa were also collected.

\subsubsection{Anthropometric Measurements and Morbidity}

For each children, sex, age, weight and height a well as morbidity indicators were recorded. Age was determined using official documents such as birth certificate or equivalent, health record, birth record if available. If not, the calendar of events was used to estimate the age of the children.

Anthropometric measures including height and weight of each participant were determined using standard techniques [13]. The child weight was measured using a UNISCALE type SECA Gmbh \& co. kg, model 8811021659 with an accuracy of 100 g. The height was measured using a wooden SHORR measuring board graduated in centimeter with precision to the millimeter. Arm circumference measurement was performed using the mnemonic tape [14]. These parameters were compared against the WHO recommended standards for different age to determine the anthropometric status of children.

Morbidity data include occurrence of diarrhea and/or fever in the previous 15 days [15].

\subsubsection{Food Diversity}

Food consumption data was collected using the 24-hour recall. Foods have were classified into six food groups as recommended by WHO. Dietary diversity and food variety score was evaluated using the country-specific WHO guide $[16,17]$. Dietary diversity indicator is the sum of scores in the six food groups and is therefore ranged from 0-6. The Minimum Dietary diversity (MDD) indicator is calculated based on consumption of at least four of the following six food groups as recommended by WHO and included: (1) starchy foods (cereals, roots and tubers), (2) legumes and nuts, (3) dairy products (milk, yogurt and Cheese), (4) Eggs, meat, fish, poultry and offal), (5) vitamin A-rich fruits and vegetables; and (6) other fruits and vegetables [18]. Response options were marked and one point (1) was assigned if the food was consumed and zero points $(0)$ if food not consumed 
[19]. The dietary diversity indicator was the sum of the scores of the six food groups from 0 to 6 . The food variety was calculated as the number of foods items consumed over a 24-hour period [20, 21]. Minimum Dietary Diversity (MDD) is calculated on the basis of a consumption of at least four of the six food groups. Consumption $\leq 3$ food groups was considered to be low dietary diversity, while 4 groups of foods considered as minimum dietary diversity and $\geq 5$ food groups such as high dietary diversity [18].

\subsubsection{Serum Retinol Concentration}

At baseline and endline, venous blood samples were taken early in the morning, from fasted children using a needle fitted to a $5 \mathrm{ml}$ non-heparinised tube. Blood was protected from light, placed on ice and transported immediately to the medical laboratory of the District Hospital. Blood samples were then centrifuged at $1000 \mathrm{~g}$ for $10 \mathrm{~min}$ at $4^{\circ} \mathrm{C}$; serum was separated into aliquots, the tubes wrapped in aluminium foil to protect the contents from light and stored at $-18^{\circ} \mathrm{C}$ until analysis. Serum retinol concentration was measured in duplicate, using high-performance liquid chromatography [22], at the laboratory of the Unité de Formation et de Recherche en Sciences de la Santé in Burkina Faso. We used WHO cut-off to define low and very low serum retinol as $<0.7 \mu \mathrm{mol} . \mathrm{L}^{-1}$ and $<0.35 \mu \mathrm{mol} . \mathrm{L}^{-1}$ respectively.

\subsection{Data Analyses}

Analyzes were performed using SPSS software for Windows version 24.0. Group differences in socio-economic and anthropometric variables without normal distribution were tested using the Mann-Whitney U-test for continuous variables and the chi-square test was used for categorical variables. The McNemar test was used to compare changes in the prevalence of low serum retinol and dietary diversity within groups for categorical variables. The paired t test or Wilcoxon test was used to assess changes in mean serum retinol concentration, depending on whether or not the variable was normally distributed. The differences between group $1\left({ }^{\phi} \mathrm{Gm}\right)$ and group $2\left({ }^{\phi} \mathrm{Gm}\right)$ for serum retinol concentration were tests using the independent samples $t$ test. Multiple linear regression analysis was used to appraise the effect of the treatment on serum retinol concentration. For all tests, a p-value less than 0.05 was considered significant

\section{Results}

Characteristics of the study participants and their households at baseline are summarized in Table 1. For most characteristics, the two groups were nearly similar. In the control group $\left({ }^{\phi} \mathrm{Gm}\right)$, $84.9 \%$ of households had agriculture as their main source of income, as compared to $79.3 \%$ in treatment group ( $\left.{ }^{\mathrm{G}} \mathrm{Gm}\right)$.

Regarding food consumption, there was no significant difference. An average diversity score of $2.82 \pm 0.9$ was evaluated in control group $(\Phi \mathrm{Gm})$ against $3.2 \pm 1.0$ in treatment group $\left({ }^{\phi} \mathrm{Gm}\right)$, with non-significant difference $(\mathrm{p}=$ 0.758 ) between the two groups. Statistical analyzes showed a non-significant difference in nutritional status (WAZ ( $\mathrm{p}=$ $0.734)$, HAZ $(p=0.518)$, WHZ $(p=0.792))$ between the groups respectively before the intervention. Our results show that $36.7 \%$ and $38.3 \%$ of children respectively $60 \%$ and $63 \%$ had diarrhea and fever respectively in control group $\left({ }^{\phi} \mathrm{G} m\right)$ and in treatment group $\left({ }^{\phi} \mathrm{Gm}\right)$.

Table 1. Socio-economic characteristics of the study population at baseline.

\begin{tabular}{|c|c|c|c|}
\hline & Group 1 ( $\$ \mathbf{G m})$ & Group $2(\phi \mathbf{G m})$ & $n$-yalue \\
\hline Households characteristics & $\mathbf{n}=\mathbf{5 9}$ & $\mathbf{n}=\mathbf{6 0}$ & $p$-vaiue \\
\hline Marital status (\%) & 90.6 & 94.8 & \\
\hline Polygamy (\%) & 58.5 & 66.7 & \\
\hline \multicolumn{4}{|l|}{ Type and education level (\%) } \\
\hline No school & 50.8 & 60.3 & \\
\hline Koranic school & 18.9 & 12.1 & \\
\hline literate & 20.8 & 22.4 & \\
\hline Secondary & 5.7 & 3.4 & \\
\hline Superior & 0 & 0 & \\
\hline \multicolumn{4}{|c|}{ Main source of household income (\%) } \\
\hline Without income & 11.3 & 10.3 & \\
\hline Trade & 3.8 & 6.9 & \\
\hline Agriculture & 84.9 & 79.3 & \\
\hline Fruit and vegetable growing (\%) & 24.5 & 34.5 & \\
\hline Knowledge of Moringa (\%) & 78.0 & 73.6 & \\
\hline Average age (months) & 19.88 & 20.27 & - \\
\hline Sex (\% boys) & 50.0 & 56.7 & - \\
\hline Low dietary diversity (\%) & 27.7 & 11.3 & - \\
\hline DDS mean \pm SD & $2.82 \pm 0.9$ & $3.2 \pm 1.0$ & 0.758 \\
\hline FVS mean \pm SD & $3.67 \pm 1.6$ & $3.71 \pm 1.4$ & - \\
\hline Diarrhea (\%) & 36.7 & 38.3 & - \\
\hline Fever $(\%)$ & 60.0 & 63.3 & - \\
\hline $\mathrm{HAZ}$ mean $\pm \mathrm{SD}$ & $-2.33 \pm 1.50$ & $-2.15 \pm 1.61$ & 0.518 \\
\hline $\mathrm{WHZ}$ mean $\pm \mathrm{SD}$ & $-2.31 \pm 0.84$ & $-2.20 \pm 0.81$ & 0.792 \\
\hline WAZ mean \pm SD & $-2.89 \pm 0.88$ & $-2.72 \pm 0.98$ & 0.734 \\
\hline
\end{tabular}


Table 2 below shows the results on serum retinol and the anthropometric status of pre-school children in rural area of Gaongo. Between the baseline and the end of the intervention the nutritional status of the children improved in both groups. The average WHZ index reflecting acute malnutrition increased in both groups. It increased from $-2.31 \mathrm{z}$-score to $1.86 \mathrm{z}$-score in control group ( $\left.{ }^{\phi} \mathrm{Gm}\right)$ and from $-2.20 \mathrm{z}$-score to $-1.88 \mathrm{z}$-score in treatment group $\left({ }^{\phi} \mathrm{Gm}\right)$ and the increase was statistically significant in the groups $(\mathrm{p}<0.001)$. However, the slight increase observed on height for age z-score (HAZ) is not statistically significant $(\mathrm{p}=0.168$ for control group $\left.\left({ }^{\phi} \mathrm{Gm}\right)\right)$ and $\mathrm{p}=0.337$ for treatment group $\left({ }^{\phi} \mathrm{Gm}\right)$.

The study found that the mean serum retinol concentration in pre-school children was below the threshold for vitamin A deficiency $\left(0.7 \mu \mathrm{mol} . \mathrm{L}^{-1}\right)$ in both groups. After intervention, mean serum retinol concentrations increased significantly from $0.64 \mu \mathrm{mol} . \mathrm{L}^{-1}$ to $0.73 \mu \mathrm{mol} . \mathrm{L}^{-1}(\mathrm{p}<0.001)$ in control group $\left({ }^{\Phi} \mathrm{Gm}\right)$ and $0.64 \mu \mathrm{mol} . \mathrm{L}^{-1}$ to $0.74 \pm 0.05 \mu \mathrm{mol} . \mathrm{L}^{-1}$ (p $<0.001)$ in treatment group $\left({ }^{\top} \mathrm{Gm}\right)$. There was a significant increase in mean serum retinol concentration $(p<0.001)$ by sex in both groups. The change between the two groups was not statistically significant.

The study assessed the proportion of children in vitamin A declines in rural areas. At baseline, the proportion of children with serum retinol deficiency was $56.8 \%$ in control group $\left({ }^{\phi} \mathrm{Gm}\right)$ and $53.8 \%$ in treatment group $\left({ }^{\phi} \mathrm{Gm}\right)$, decreasing to $22 \%$ and $19.2 \%$ respectively $(\mathrm{p}<0.05)$ after intervention. However, no group recorded an average serum retinol concentration of less than $0.35 \mu \mathrm{mol} . \mathrm{L}^{-1}$, defining a very deficient situation.

Table 2. Changes in anthropometric status and serum retinol before and after intervention of the study population.

\begin{tabular}{|c|c|c|c|c|c|c|c|c|}
\hline & \multirow{2}{*}{ Baseline } & \multicolumn{4}{|c|}{ Group 1 (\$Gm) } & \multicolumn{3}{|c|}{ Group 2 ( $\phi \mathrm{Gm})$} \\
\hline & & End line & Change $\uparrow$ & $p$-value & Baseline & End line & Change $\dagger$ & $p$-value \\
\hline \multicolumn{9}{|l|}{ Nutritional status* } \\
\hline $\mathrm{HAZ}($ mean $\pm \mathrm{SD})$ & $-2.33 \pm 1.5$ & $-2.22 \pm 1.4$ & $+0.93 \pm 0.43 \ddagger$ & 0.168 & $-2.15 \pm 1.6$ & $-2.12 \pm 1.6$ & $+0.05 \pm 0.40 \ddagger$ & 0.337 \\
\hline WHZ $($ mean $\pm \mathrm{SD})$ & $-2.31 \pm 0.8$ & $-1.86 \pm 0.7$ & $+0.31 \pm 0.51 \ddagger$ & 0.001 & $-2.20 \pm 0.8$ & $-1.88 \pm 0.8$ & $+0.30 \pm 0.63 \$$ & $<0.001$ \\
\hline \multicolumn{9}{|l|}{ Serum retinol status } \\
\hline \multicolumn{9}{|l|}{ Serum retinol concentration* $\left(\mu\right.$ mol. $\left.^{-1}\right)$} \\
\hline Boys & $0.62 \pm 0.1$ & $0.71 \pm 0.08$ & & $<0.001$ & $0.65 \pm 0.1$ & $0.74 \pm 0.04$ & & $<0.001$ \\
\hline Girls & $0.66 \pm 0.09$ & $0.75 \pm 0.06$ & & $<0.001$ & $0.64 \pm 0.1$ & $0.74 \pm 0.04$ & & $<0.001$ \\
\hline \multicolumn{9}{|l|}{ Serum retinol concentration $*<0.70 \mu \mathrm{mol}^{-1} \mathrm{I}^{-1}(\%)$} \\
\hline Total & 56.8 & 22.0 & -34.4 & $<0.05$ & 53.8 & 19.2 & -34.6 & $<0.05$ \\
\hline Boys & 61.9 & 31.6 & & & 58.6 & 24.1 & & \\
\hline Girls & 52.2 & 13.6 & & & 47.8 & 13.0 & & \\
\hline Serum retinol concentration $*<0.35 \mu \mathrm{mol}^{-1} \mathrm{l}^{-1}(\%)$ & 0 & 0 & - & & 0 & 0 & - & \\
\hline
\end{tabular}

$\phi \mathrm{Gm}=$ Group of children (witness) not receiving Moringa

${ }^{\phi} \mathrm{Gm}=$ Group of children receiving $30 \mathrm{~g}$ Moringa leaves powder per day

* Values are means \pm standard deviation

$\dagger$ Difference of means or proportion (after intervention minus baseline)

+ Comparison of difference not significantly between ${ }^{\phi} \mathrm{Gm}$ and ${ }^{\phi} \mathrm{Gm}$

Table 3 shows the predictors of serum retinol change in the study population. Our results show that treatment was not a significant determinant in the change in serum retinol status $(p=0.379)$. However, a high serum retinol concentration, dietary diversity, or household size were associated with the slight increase in serum retinol observed after intervention.

Table 3. Potentials predictors of serum retinol change in pre-school children.

\begin{tabular}{|c|c|c|c|}
\hline & \multicolumn{2}{|l|}{ Linear regression } & \multirow{2}{*}{$p$-value } \\
\hline & Coefficient of regression & Standard error & \\
\hline Treatment group & 0.453 & 0.037 & 0.379 \\
\hline Retinol pre intervention & 0.362 & 0.053 & $<0.001$ \\
\hline Frequency of consumption of $\mathrm{VA}^{*}$ rich foods & 0.014 & 0.013 & 0.317 \\
\hline Dietary diversity $^{* *}$ & 0.020 & 0.009 & 0.03 \\
\hline Household size & 0.002 & 0.001 & 0.003 \\
\hline
\end{tabular}

* Vitamine A

** Minimum dietary diversity

\section{Discussion}

This study was carried out to assess the effectiveness of Moringa leaves powder consumption in improving the anthropometric status and serum retinol concentration of preschool children. Findings suggest significant improvement in
WHZ and WAZ in both groups, but a non-significant difference in nutritional status (WAZ $(\mathrm{p}=0.734)$, HAZ ( $\mathrm{p}=$ $0.518)$, WHZ $(p=0.792)$ ) between the groups respectively before the intervention were found. After intervention, the comparison of difference of the three nutritional index was not significant between control group and treatment group 
(WAZ $(\mathrm{p}=0.510)$, HAZ $(\mathrm{p}=0.473)$, WHZ $(\mathrm{p}=0.318))$. The slight deterioration in children's health status during followup in both groups would explain the good nutritional status despite the low dietary diversity observed in the study area and specifically among the children studied. Indeed, an extensive descriptive analysis of daily diet of preschool children of the study area showed that the foods most commonly eaten by these children are cereals and tubers, vegetables (especially leafy vegetables sauces), and the leafy vegetables used prepare sauce, was mainly hibiscus, baobab, corte, okra, tomato, onion [7].

There were very high levels of VA deficiency among preschool children up to $56.8 \%$ and $53.8 \%$ in control Group and treatment group respectively, which is a major public health concern. VA inadequacy levels much higher than the $36.2 \%$ low serum concentration reported by Nana in preschool children in rural Burkina Faso [23].

After 12 months of intervention, the proportions of children with low serum concentration decreased significantly in both groups. Despite the significant decrease in control group $\left({ }^{\phi} \mathrm{Gm}\right)$, the proportion of $22 \%$ still remains above the $20 \%$ threshold according to WHO. In treatment group $\left({ }^{\oplus} \mathrm{Gm}\right)$ the proportion of children with VA deficiency fell below the $20 \%$ threshold but still remains above $15 \%$. As suggested by Wasanwisut the intervention was considered effective since the deficiency rate was down to $15 \%$ or less in all intervention groups, considering significantly difference [24].

Factors other than VA intake may also contribute to low serum retinol values, and these should not be overlooked. One of those factors is underlying infection, which is known to reduce serum retinol and makes serum retinol non-specific of VA deficiency $[25,26]$. Data on children's health status, including diarrhoea and fever, did not show significantly correlation with serum retinol. It is important to mention that all children were dewormed with mebendazole $500 \mathrm{mg}$ at the beginning of the intervention. Another factor that may explain the persistence of more than $10 \%$ low serum retinol values is the presence of concurrent nutritional deficiencies which may act as limiting factors. Indeed, it is recognized that zinc deficiency is widespread among children around the world and is known to affect growth [27] and interacts with VA [28].

In both groups, sex appears to be a determinant of serum retinol concentration across the high proportions of VA deficiency in boys compared to girls. This result could be due to their vulnerability compare to female. Previous studies have reported that boys have the highest risk of vitamin A deficiency even though the reasons for their vulnerability remain largely unexplained [29].

A mean serum retinol concentration below the threshold defining a VA deficiency $\left(<0.7 \mu\right.$ mol. $\left.\mathrm{L}^{-1}\right)$ is recorded in both groups before the intervention. Significant improvement in serum retinol was observed after intervention in both groups. However, the comparison between the two groups ( ${ }^{\phi} \mathrm{Gm}$ and $\left.{ }^{\phi} \mathrm{Gm}\right)$ showed that the difference is not statistically significant $(\mathrm{p}=0.838)$.
In the absence of an effective control group under wellcontrolled conditions, it is difficult to attribute the decrease in VA deficiency (from $22 \%$ to $20 \%$ ) observed in treatment Group $\left({ }^{\dagger} \mathrm{Gm}\right)$ to the intervention, but considering the low dietary diversity and the almost homogeneous food variety in the studied community and in both groups, a minor effect on the consumption of Moringa leaves would be likely.

Our findings showed that the intervention was not effective enough in the change in serum retinol status in children. The change in serum retinol was significantly influenced by serum retinol concentration at baseline.

These results corroborates previous studies [2, 23]. It could probably be explained by the duration of the intervention and the poorly controlled feeding of children in both groups.

High dietary diversity and household size was also associated with the slight increase in serum retinol. Similar results for household size were reported by Nana in preschool children [23]. Kjolhede et al. reported similar results from Java; an obvious explanation, according to the authors, would be that the more people have to be fed in the family, the less VA per person is available [30].

To better conclude on the impact of Moringa on serum retinol status, the study should be repeated in a long-term controlled trial by combining oil in food consumption.

Although dietary diversity has been associated with a slight increase in serum retinol, our previous results showed that three major foods make up the bulk of the daily diet of preschool children in the area, namely, Tô (Tô is the staple food in Burkina Faso, consisting of a cereal-based thick porridge, and is adapted to several types of sauces), porridge and rice. Our previous results also showed that only a small proportion of same preschool children consumed fruits and vegetables rich in vitamin A, meat, fish and eggs [7]. Low dietary diversity is a major problem in developing countries whose daily diet is usually based on starchy foods (cereals, tubers) with one or two additional components [31]. In the developing world, multiple micronutrient deficiencies generally coexist [32] and combined supplementation becomes an appealing strategy, although controlled studies have indicated a likely competition in absorption of iron and zinc [33] and the possible adverse effect of iron supplementation on VA status [34].

In view of the important results on the consumption of Moringa leaves powder in the nutritional recovery from severe acute malnutrition, consumption of Moringa leaves powder should be encouraged to improve the nutritional status of children, and prevent against some micronutrient deficiencies as iron and Vitamin $A$ in view of the nutritional value of its leaves commonly used in Burkina Faso [6].

In the study area, among leafy vegetables, Moringa oleifera is the most available (during dry or rainy season) but more rarely consumed because of eating habits. Previous study showed that $85.5 \%$ of preschoolers' mothers know the beneficial effects of Moringa leaves on health [7].

Therefore, the promotion of Moringa leaves consumption should be complemented by additional approaches to 
increase VA intake, as well as through public health measures such as deworming programs, to enhance its effectiveness in the fight against VA deficiencies and many other micronutrients.

\section{Conclusion}

Our study has, to a lesser extent, assessed the effect of Moringa leaves powder consumption on the nutritional status and serum retinol concentration of pre-school children in rural Burkina Faso. According to nutritional status, between the baseline and the end line of the intervention the anthropometric status of the children improved in both groups, but a non-significant difference in nutritional status between the groups after the intervention were found. Regarding food consumption, there was no significant difference. Dietary diversity score was evaluated in control group $\left({ }^{\Phi} \mathrm{Gm}\right)$ and treatment group $\left({ }^{\Phi} \mathrm{Gm}\right)$, with non-significant difference between the two groups.

Significant improvement in serum retinol was observed after intervention in both groups. However, the comparison of difference between the two groups ( ${ }^{\phi} \mathrm{Gm}$ and ${ }^{\phi} \mathrm{Gm}$ ) showed that the difference is not statistically significant. There was a significant increase in mean serum retinol concentration by sex in both groups. The change between the two groups was not statistically significant.

Our findings showed that the intervention was not effective enough in the change of serum retinol status in children. However, a high serum retinol concentration, dietary diversity, or household size were associated with the slight increase in serum retinol observed after intervention.

The results showed that Moringa is interesting in improving the nutritional status of children even if its effect on the improvement of serum retinol status is limited. It seems compelling to supplement with additional approaches over a longer period, under controlled conditions to better appreciate the effect of Moringa in improving the nutritional status and in VA status and other micronutrient of vulnerable children.

\section{Acknowledgements}

The authors are very grateful to ZOMA L. Robert for technical support specially data analyses.

\section{Conflicts of Interest}

The authors declare that they have no conflicts of interest.

\section{Limitations}

The main limitation of the study was the poor control of the different quantity of food consumed by preschool children, which made it impossible to assess the adequacy ratio of nutrients.

\section{References}

[1] FAO/WHO, 1992. Nutrition and development-an overall assessment. International Conference on Nutrition, Rome. In 1992.

[2] Delisle H, Zagré N M, Bakari S, Codja P Z R. 2003. A foodsystem approach to vitamin A deficiency. Food Agric Nutr. (32):40-50.

[3] Wasantwisut E, Chittchang U. et Sinawat S. 2000. Moving a health system from a medical towards a dietary approach in Thailand. Food Nut Bull. (21):157-60.

[4] Ndong M, Wade S, Dossou N G A and R G. 2007. Nutritional value of Moringa oleifera, study of the bioavailability of iron, effect of the enrichment of various Senegalese traditional dishes with the powder of the leaves. Afric J Food Agr Nutr Dev. 7 (3): 17.

[5] Moyo B, Masika P J H A and M V. 2011. Nutritional characterization of Moringa (Moringa oleifera Lam.) leaves. African J Biotechnol. 10 (60):12925-33.

[6] Zongo U, Zoungrana S L, Savadogo A, Traoré A S. 2013. Nutritional and Clinical Rehabilitation of Severely Malnourished Children with Moringa oleifera Lam. Leaf Powder in Ouagadougou (Burkina Faso ). Food and Nutrition Sciences:991-7.

[7] Zongo U, Zoungrana S L, Savadogo A, Traoré A S. 2017. Assessment of Dietary Diversity and Vitamin A-Rich Foods Consumption of Pre-School Children in Rural Community in Burkina Faso, an Impact Study Approach. Austin J Nutri Food Sci. 5 (1):1-5.

[8] Tété-Bénissan A, Lawson-Evi K, Kokou K, and Gbéassor M. 2012. Effect of Moringa oleifera Lam. leaves powder on the evolution of hemogram profile in togolese undernourished children: evaluation on HIV-positive patients. Afric J Food Agr Nutri Dev. 12 (2):6007-26.

[9] Yang R Y, Lien-Chung C, Jenn-Chung H, Brian Weng B C, Manuel Palada M L C and VL. 2006. Propriétés Nutritionnelles et Fonctionnelles des Feuilles de Moringa; Du Germoplasme, à la Plante, à l'aliment et à la santé. World Veg Center.

[10] WHO. 2007. Protein and amino acid requirements in human nutrition. Report of a joint $\mathrm{FAO} / \mathrm{WHO} / \mathrm{UNU}$ Expert Consultation (WHO Technical Report Series $n^{\circ}$ 935). Geneva: World Health Organization.

[11] P G. 2009. Nutritional needs. In Child and Nutrition: A Guide for Professionals Edition, Office of Birth and Childhood (ONE), Benoît Parmentier Chaussée de Charleroi, 95 - 1060 Bruxelles D/2009/74.80/11. 13-32.

[12] Nambiar VS, Parnami S. 2008. Standardization and Organoleptic Evaluation of Drumstick ( Moringa oleifera ) Leaves Incorporated Into Traditional Indian Recipes. Trees Life J. 3:2-6.

[13] Fenfang L, Lynne R W, Rachel N, Marie K F, Yvette C P, Randall N, Andrea B, Ursula M, Jonathan D, and Carol J B. 2016. Anthropometric Measurement Standardization in the US Affiliated Pacific: Report from the Children's Healthy Living Program. Am J Hum Biol. 28 (3): 364-371. 
[14] Cogill B, 2003. Antropometric and indicators measurement guide. FANTA, AED, Washington, D. C.

[15] Kalter H D. 1991. Validation of the diagnosis of childhood mortality using maternal health interviews. Int J Epidemiol. (20):193-8.

[16] FANTA. 2006. Working Group on Infant and Young child feeding Indicators. Developing and validating simple indicators of dietary quality and energy intake of infants and young children in developing countries: summary of fidings from analysis of 10 data sets. Washinton.

[17] WHO. 2009. Indicators for assessing infant and young child feeding practices. Part II: measurement. WHO Press.

[18] Arimond M, Wiesmann D, Becquey E, Carriquiry A, Daniels M, Deitchler M, fanou-fogny N, Joseph M, Kennedy G, Martin-Prevel Y et Torheim L E. 2010. Simple food group diversity indicators predict micronutrient adequacy of women's diets in 5 diverse, resource-poor settings. J Nutr. (140):2059S-69S.

[19] Kuhnlein H, Pelto G H. 1997. Culture, Environment, and Food to Prevent Vitamin A Deficiency. 7757 p.

[20] FANTA. 2004. Increased number of different foods or food groups consumed. Measuring household food consumption: A technical guide.

[21] WHO. 2009. Child growth standards and the identifiation of severe acute malnutrition in infants and children.

[22] Sapin V, Alexandre M C, Chaïb S, Bournazeau J A, Sauvant P, Borel P, Jacquetin B, Grolier P, Lemery D, Dastugue B, AzaisBraesco V. 2000. Effect of vitamin A status at the end of term pregnancy on the saturation of retinol binding protein with retinol. Am J Clin Nutr. 71 (2):537-43.

[23] Nana C, Brouwer I, Zagré N, Kok F, Traoré A S. 2005. Impact of promotion of mango and liver as sources of vitamin A for young children: a pilot study in Burkina Faso. Public Health Nutr. 9 (06):808-13.
[24] Wasantwisut E. 2002. Recommendations for monitoring and evaluating vitamin A programs: outcome indicators. J Nutr. (132):2940S-2942S.

[25] Richard D S, Martin W B. 2008. Nutrition and health in developing countries. Second Edition. ISBN: 978- 1-934115$24-4$.

[26] Victor M A, and Shawn K B. 2005. Vitamin A deficiency and child survival in sub-Saharan Africa: A reappraisal of challenges and opportunities. Food and Nutr Bull, 26 (4):348355 .

[27] Enju L, Laura P, Masha S, Sarah K, Christopher P D, Dariush M, and Wafaie W F. 2018. Effect of Zinc Supplementation on Growth Outcomes in Children under 5 Years of Age. Nutrients, 10, 377.

[28] Christian P, West K J. 1998. Interactions between zinc and vitamin A: an update. Am J Clin Nutr. (68):435S-441S.

[29] Pilch S M. 1987. Analysis of vitamin A data from the health and nutrition examination surveys. J Nutr. (117):636-40.

[30] Kjolhede C L, Stallings R Y, Dibley M J, Sadjimin T, Dawiesah S P S. 1995. Serum retinol level among preschool children in Central Java: demographic and socioeconomic determinants. Int J Epidemiol. (24):399-403.

[31] WHO. 2006. Child Growth Standards based on length/ height, weight and age. Acta Paediatr. 95 (450):76-85.

[32] Allen L H. 2002. Iron supplements: scientific issues concerning efficacy and implications for research and programs. J Nutr. (132):813S-9S.

[33] O'Brien K O, Zavaleta N, Caulfield L E, Wen J, Abrams S A. 2000. Prenatal iron supplements impair zinc absorption in pregnant Peruvian women. J Nutr. (130):2251-5.

[34] Wieringa F T, Dijkhuizen M A, West C E, Thurnham D I, Muhilal van der M J. 2003. Redistribution of vitamin A after iron supplementation in Indonesian infants. Nutr Am J Clin. (77):651-7. 